\title{
Experimental Analysis of Thickness Reduction Limits in Ultra Thin Stainless Steel Foil Rolling
}

\author{
Junichi TATENO, ${ }^{1)}$ Toshiki HIRUTA, ${ }^{1)}$ Shigefumi KATSURA, ${ }^{2)}$ Atsutaka HONDA, ${ }^{2)}$ Takeshi MIYATA ${ }^{2)}$ and \\ Akinobu KAMIMARU ${ }^{2)}$
}

1) Steel Research Laboratory, JFE Steel Corporation, Chiba, 260-0835 Japan.

2) East Japan Works, JFE Steel Corporation, Chiba, 260-0835 Japan.

(Received on December 3, 2010; accepted on January 31, 2011)

\begin{abstract}
In rolling of ultra thin stainless steel foil, there are two rolling limits. One is owing to elastic deformation of work rolls, and the other is owing to edge crack of rolled foil. In this paper, fundamental investigation was conducted about the basic characteristic of the rolling limits of ultra thin stainless steel foil. The influence of several rolling conditions on minimum thickness and behavior of edge crack were investigated experimentally. This paper provides new formula to predict the minimum thickness in ultra thin foil rolling. The relation between the edge crack depth and the rolling conditions is also discussed. The edge crack expands with rolling passes. However, the degree of the edge crack at same foil thickness shows different behavior depending on rolling conditions. The depth of edge crack rolled by small diameter work rolls is shallower than that of same thickness foil rolled by large diameter work rolls. Moreover, when Young's modulus of work rolls is high, it turns out that the edge crack is small. Based on detailed observation of the foil edge phenomenon, good correlation between edge crack depth and foil thickness at extreme edge portion is found. From those experimental results, it is suggested that the rolling conditions advantageous to control edge drop are effective to suppress edge crack expansion.
\end{abstract}

KEY WORDS: rolling; stainless steel; foil; lubricant; thickness; crack; work roll.

\section{Introduction}

The utilization of metallic foil has been expanded in recent years with sophistication of electrical machinery and the parts for automobiles, etc., and the demands for the thinner foil become strong. ${ }^{1,2)}$ For example, stainless steel foil has been used for metallic substrate of automotive catalytic converter for two decades, because the property of stainless foil as the honeycombs substrate shows good performance in exhaust gas resistance and heat resistance. ${ }^{3-5)}$ In such usages, ultra thin foil of $30 \mu \mathrm{m}$ or less is strongly hoped for as to achieve higher performance. Those products can contribute to earth environment.

The stainless steel foil manufactured by rolling method is regarded as a hard material because of high flow stress and low ductility. Though such ultra thin foils were often produced under low productivity with a lot of rolling passes. So, the rolling techniques that enable more efficient production have been expected strongly.

Therefore it is necessary to clarify the characteristic of ultra thin foil rolling. For rolling of the ultra thin stainless steel foil, it has been discussed the rolling limits where foil thickness doesn't decrease by elastic flattening of the rolls a little. Several attempts have been made to describe the thickness reduction limit in rolling caused by roll flattening. ${ }^{7-11)}$ It has been shown that the rolling conditions such as roll diameter or Young's modulus of the work rolls influence on the rolling limit owing to the roll flattening. How- ever, some differences in predicting minimum thickness can be seen among those past researches. Those differences may be caused by the different conditions of rolling experiments. Then, it is necessary to experiment with rolling conditions similar to that of industrial foil rolling.

On the other hand, rolling limit caused by the edge crack of the rolled foil is also important. It has not been discussed so much to date, although the edge crack characteristic is an important viewpoint of commercial manufacturing.

In this paper, fundamental investigation was conducted about the basic characteristics of the rolling limits of ultra thin stainless steel foil. The influences of several rolling conditions on minimum thickness and behaviour of edge crack are investigated experimentally.

\section{Rolling Limit Owing to Elastic Deformation of Work Rolls}

\subsection{Laboratory-scale Rolling Mill and Experimental Conditions}

Table 1 shows the experimental conditions to investigate the thickness reduction limit in foil rolling. The annealed ferritic stainless steel of $50 \mu \mathrm{m}$ thick was prepared as mother materials. A 4-high laboratory-scale reversing mill was used for multi-pass rolling. Two sizes of work rolls, $50 \mathrm{~mm}$ and $40 \mathrm{~mm}$ in diameter, were examined. In addition to normal steel work rolls, sintered hard alloy (tungsten carbide) work rolls with high Young's modulus were also applied. As the 
lubricant oils, mineral oils of three kinds of viscosity, 7.5, $15,22 \mathrm{~mm}^{2} / \mathrm{s}$ at $40^{\circ} \mathrm{C}$ were arranged. The rolling conditions such as rolling force and strip tension set equally in each rolling pass, and the foil thickness after each pass was measured and compared.

The foil thickness after each rolling pass is shown in Fig. 1. The reduction rates of foil thickness after each pass were quite different according to the conditions of lubricant oils or work rolls. Concerning with lubricants, high viscosity oils contribute to obtain high reduction of thickness. As for the work roll conditions, small diameter and high Young's modulus were effective to obtain high reduction of thickness. Here, on which conditions, foil rolling forward minimum thickness was interrupted by strip breakage due to edge crack.

\subsection{Extrapolation of Minimum Thickness}

The rolling limit caused by roll flattening means the phenomenon that strip thickness doesn't decrease even if the rolling pressure is loaded. The contour of work roll is flattened by elastic deformation as shown in Fig. 2 .

Based on the experimental results shown in Fig. 1, rolling limit owing to roll flattening was studied. Figure 3(a) shows

Table 1. Experimental conditions of foil rolling.

\begin{tabular}{ll}
\hline Material & Ferritic Stainless Steel \\
& Annealed, $50 \mu \mathrm{m}$ \\
Rolling Mill & 4 Hi Reversing Mill \\
Work Rolls & $50 \mathrm{~mm}$ in diameter \\
& $($ Steel: $E=206 \mathrm{GPa})$ \\
& $40 \mathrm{~mm}$ in diameter \\
& $($ Steel: $E=206 \mathrm{GPa})$ \\
& $40 \mathrm{~mm}$ in diameter \\
& $(\mathrm{WC}: E=539 \mathrm{GPa})$ \\
& $6 \mathrm{kN} / \mathrm{mm}$ \\
Rolling force & $40 \%$ of yield stress \\
Strip tension & $100 \mathrm{~m} / \mathrm{min}$. \\
Rolling velocity & Mineral oil A $\left(7.5 \mathrm{~mm}^{2} / \mathrm{s}\right.$ at $\left.40^{\circ} \mathrm{C}\right)$ \\
Lubricant oils & Mineral oil B $\left(15 \mathrm{~mm}^{2} / \mathrm{s}\right.$ at $\left.40^{\circ} \mathrm{C}\right)$ \\
& Mineral oil C $\left(22 \mathrm{~mm}^{2} / \mathrm{s}\right.$ at $\left.40^{\circ} \mathrm{C}\right)$ \\
\hline
\end{tabular}

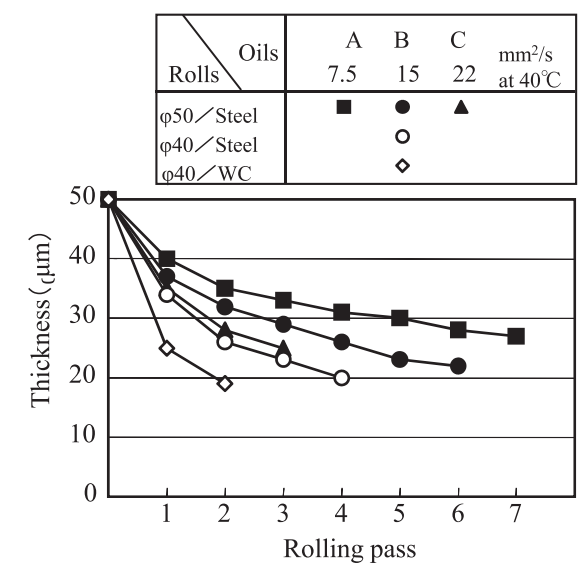

Fig. 1. Thickness at each rolling pass in foil rolling. the relation between accumulated rolling force and outlet thickness. The accumulated rolling force means sum of rolling force from first pass to the current pass. Based on Fig. 3(a), amount of reduction in thickness per rolling force: $\Delta h /$ $\Delta p$ was calculated. Figure 3(b) shows the relation between $\Delta h / \Delta p$ and thickness just at the pass. When $\Delta h / \Delta p$ becomes equivalent to zero, it means rolling limit. The outlet thickness at $\Delta h / \Delta p=0$ can be regarded as minimum thickness owing to elastic deformation of work rolls.

\subsection{Numerical Formula to Predict the Minimum Thickness}

Several attempts have been made to describe the reduction limit in rolling. Those researches were summarised in the following formula. ${ }^{7-11)}$

$$
H \min =\alpha \cdot D \cdot \mu \cdot(k-\sigma) / E .
$$

Hmin: Minimum thickness (mm),

$\alpha$ : Coefficient,

$D$ : Diameter of work rolls $(\mathrm{mm})$,

$E$ : Young's modulus of work roll $(\mathrm{GPa})$,

$\mu$ : Friction coefficient,

$k$ : Deformation resistance (GPa),

$\sigma$ : Strip tension (GPa).

Equation (1) means that the minimum thickness: Hmin is in proportion to diameter of work rolls: $D$, friction coefficient: $\mu$, and deformation resistance subtracted strip tension: $(k-\sigma)$. When the value of $\mu$ or $(k-\sigma)$ becomes small, rolling force is decreased. When the value of $D$ becomes small, rolling force is also decreased because contact length between roll and foil becomes short. If rolling force is kept small, roll flattening is suppressed. And it is inversely proportional to Young's modulus of work rolls: $E$. $E$ is a measure of the stiffness of elastic material and it influences roll flattening directly.

Over the last few decades, the coefficient: $\alpha$ in Eq. (1) has been the subject of controversy. The latest study reported by Shida ${ }^{11)}$ derived the value of $\alpha$ theoretically and experimen-

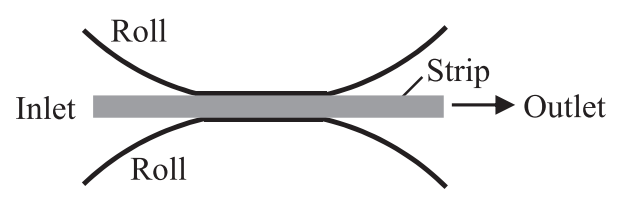

Fig. 2. Elastic deformation of work rolls.
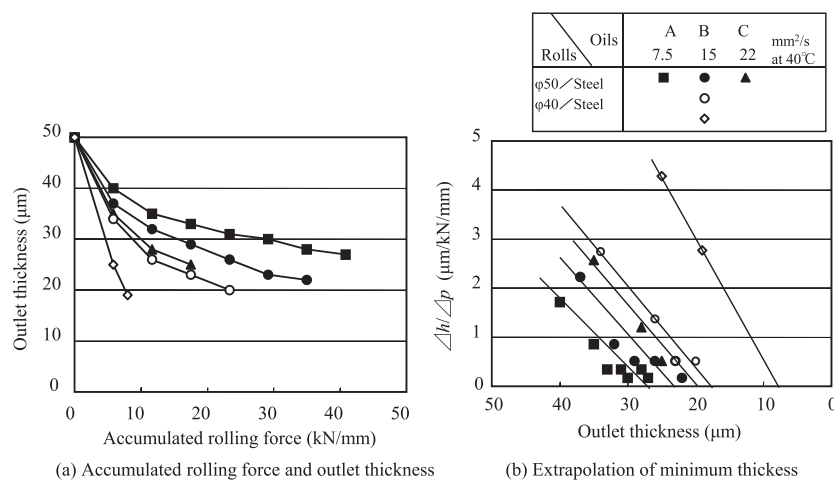

Fig. 3. Thick ness reduction limit in foil rolling. 
tally as follows.

$$
\alpha=4.13-13 \mu^{2}
$$

$\mu$ : Friction coefficient calculated by Orowan's theory.

Figure 4(a) shows the relation between minimum thickness calculated by Shida's formula and that of experimental results of this paper. There are mutually related, but not correspond in numerical absolute value. The minimum thickness calculated by the formula is almost twice larger than that of the experimental results of this paper.

This paper provides the formula with new value $\alpha$ to predict the minimum thickness as follows.

$$
\alpha=1.74 \text {. }
$$

Experimental condition on lubricant oil reflected in frictional properties. Based on calculation results using Orowan's model, $\mu=0.09,0.075,0.06$ were assigned for rolling viscosity of $7.5,15,22 \mathrm{~mm}^{2} / \mathrm{s}$ respectively.

Figure 4(b) shows the relation between minimum thickness calculated by the proposed prediction formula of this paper and that of experimental results. The minimum thickness by the formula shows good coincidence with that of experimental results.

Table 2 shows the difference of rolling conditions between
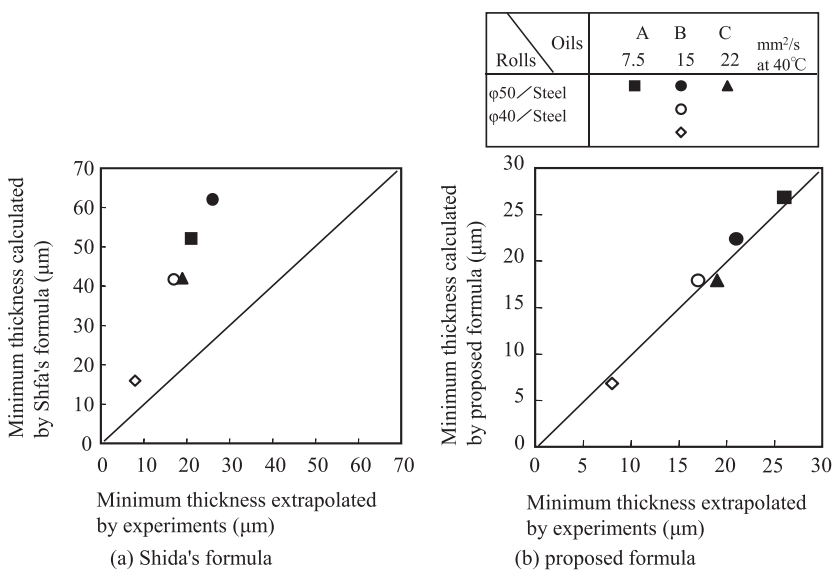

Fig. 4. Minimum thickness calculated by the prediction formula.
Shida's experiments and this paper's one. Conspicuous differences are rolling velocity and lubricant oils. In the Shida's experiments, the rolling velocity was set to $10 \mathrm{~m} / \mathrm{min}$ and this condition is remarkably small compared with actual operational condition. The rolling velocity in this paper was set to $100 \mathrm{~m} / \mathrm{min}$. In cold foil rolling, introduction of lubricant oil into roll bite is increased when the rolling velocity is high, and friction coefficient becomes small. The difference of those conditions is presumed that the difference of the parameter concerning frictional properties influenced.

\section{Rolling Limit Owing to Edge Crack}

\subsection{Expansion of Edge Crack in Foil Rolling}

In the metallic foil rolling, "rolling limit owing to the edge crack" is a big problem together with above-mentioned "rolling limit owing to roll flattening". This significant issue has not been focused on in ultra thin foil rolling. In this chapter, the relation between the edge crack of rolled foil and the rolling conditions is also investigated.

Figure 5 is macro photograph around the edge part of the foil rolled from $50 \mu \mathrm{m}$ to less than $30 \mu \mathrm{m}$ thick. In the stainless steel foil rolling, the crack generated at the edge spreads into inside, and the growing edge crack leads to strip breakage.

In general, to prevent strip breakage owing to the edge crack, strip tension is set to small during rolling. Rolling with low tension has been regarded effective to prevent strip breaking caused by stress concentration on the crack part of the edge.

However, it is necessary to understand more about edge

Table 2. Rolling conditions of Shida's experiment and this paper's one.

\begin{tabular}{lcc}
\hline & Shida's formula & Proposed formula \\
\hline Materials & Stainless steel & Stainless steel \\
Diameter of WR $(\mathrm{mm})$ & $20,60,160$ & 40,50 \\
Young's modulus $(\mathrm{GPa})$ & 304,216 & 539,206 \\
Rolling velocity $(\mathrm{m} / \mathrm{min})$. & 10 & 100 \\
Lubricant oils $\left(\mathrm{mm}^{2} / \mathrm{s}\right)$ & 10 & $7.5,15,22$ \\
\hline
\end{tabular}
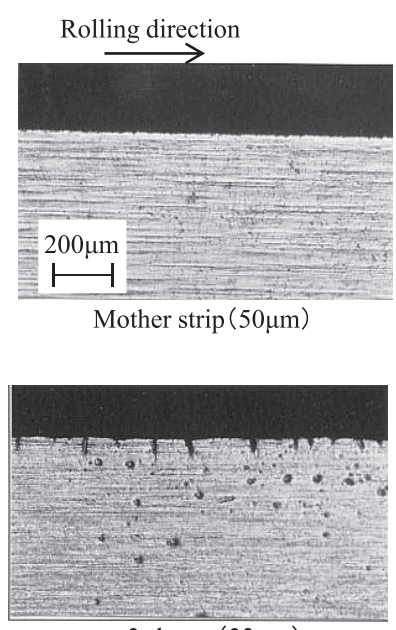

3rd pass $(32 \mu \mathrm{m})$

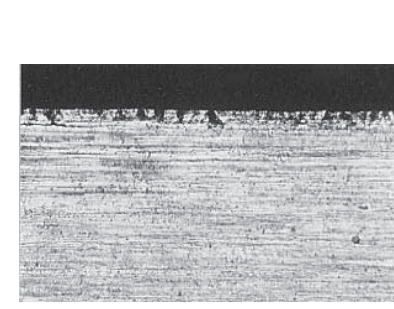

1 st pass $(39 \mu \mathrm{m})$

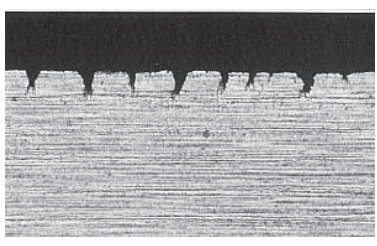

$4 \operatorname{th}(30 \mu \mathrm{m})$
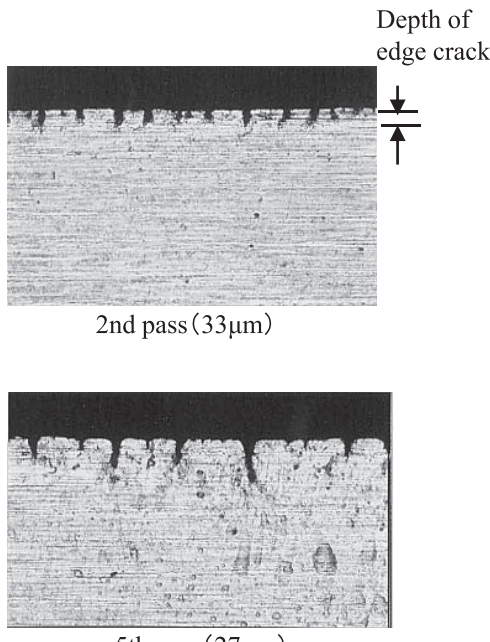

5 th pass $(27 \mu \mathrm{m})$

Fig. 5. Edge crack of rolled foil ( $\phi 50$ Steel roll, Mineral B: $7.5 \mathrm{~mm}^{2} / \mathrm{s}$ at $\left.40^{\circ} \mathrm{C}\right)$. 
crack behaviour because the ultra thin foil is very sensitive to the edge crack. Moreover, there is a problem that it becomes impossible to achieve thickness reduction when strip tension is reduced in rolling near the rolling limit. So, more effective and practical rolling technique of preventing strip breakage is desired. For this purpose, a precise experiment was carried out about growth behaviour of the edge

Table 3. Experimental conditions in foil rolling for evaluating edge crack.

\begin{tabular}{ll}
\hline Material & Ferritic stainless steel \\
& Annealed, $300 \mu \mathrm{m}$ \\
Rolling Mill & 4 Hi Reversing mill \\
Work Roll & $130 \mathrm{~mm}$ in diameter \\
& $($ Steel roll: $E=206 \mathrm{GPa})$ \\
Rolling force & $10 \mathrm{kN} / \mathrm{mm}\left(1^{\text {st }}\right.$ pass $)$ \\
& $15 \mathrm{kN} / \mathrm{mm}\left(\right.$ Excect $1^{\text {st }}$ pass $)$ \\
Strip tension & Tension A $(30 \%$ of yield stress $)$ \\
& Tension B $(60 \%$ of yield stress $)$ \\
Rolling velocity & $20 \mathrm{~m} / \mathrm{min}$. \\
Lubricant oils & Mineral oil A $\left(7.5 \mathrm{~mm}^{2} / \mathrm{s}\right.$ at $\left.40^{\circ} \mathrm{C}\right)$ \\
\hline
\end{tabular}
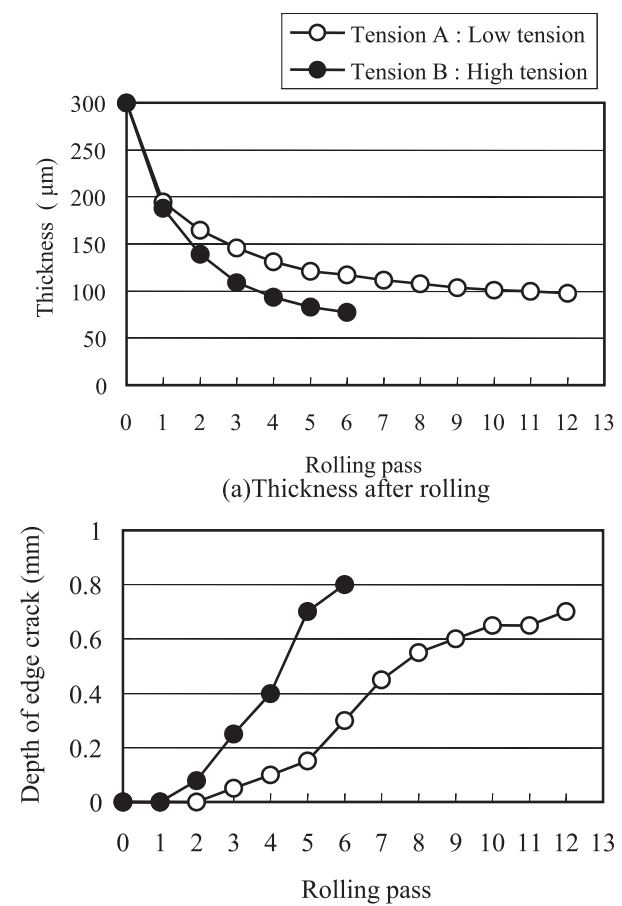

(b) Depth of edge crack and rolling pass

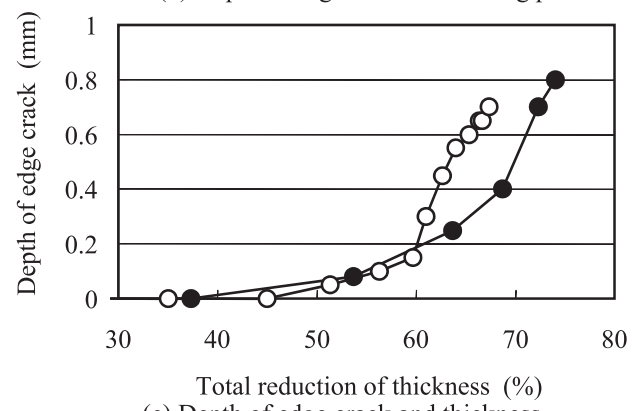

(c) Depth of edge crack and thickness

Fig. 6. Experimental results of foil rolling for evaluating edge crack. crack in ultra thin foil rolling.

\subsection{Influence of Strip Tension on Edge Crack}

Table 3 shows the experimental conditions concerning the influence of strip tension. Here, to observe the growth of edge crack in detail, rolling condition was set to emphasize roll diameter and the mother strip thickness compared with normal foil rolling. Using the work roll of $130 \mathrm{~mm}$, the stainless steel sheet of $0.3 \mathrm{~mm}$ thickness was rolled up to rolling limit. Under the other conditions such as rolling force were set to same condition. Rolling experiments were carried out with low tension (tension $\mathrm{A}$ ) and high tension (tension B). Here, tension condition A gave the tension of about $30 \%$ of deformation resistance of the material and tension condition B gave the tension of about $60 \%$. Edge crack behaviour was observed using microscope from the foil sample after each rolling pass. Degree of the edge crack is defined by the depth of edge crack tip from original edge line.

The results of the experiment are shown in Fig. 6. Figure 6(a) shows the foil thickness after each rolling pass. The thickness reduction of tension condition $\mathrm{B}$ of high tension is more advanced than tension condition A of low tension. Thickness reduction rate becomes small gradually in both conditions, and it reaches the rolling limit. Figure 6(b) shows the edge crack depth at each rolling pass. The depth of edge crack of tension condition B is bigger than that of tension condition A of low tension, as well as progress of thickness reduction. However, when comparing the relation between total reduction rate and depth of edge crack like Fig. 6(c), the edge crack of low tension condition $A$ is larger than that of high tension condition $\mathrm{B}$.

It is suggested that the influence of rolling tension, which is main factor of the stress concentration causing strip breakage must be discussed separately with growth behaviour of the edge crack.

\subsection{Edge Crack Behaviour under the Foil Rolling Con- dition}

As the next stage, the edge crack behaviour was investigated in the rolling condition for ultra thin stainless foil. The experimental condition is shown in Table 1.

Figure 7(a) shows the edge crack depth at each rolling pass. Here, foil thickness at each rolling pass is shown in Fig. 1. Figure 7(a) means that roll conditions and rolling oil conditions influence on the growth of the edge crack. Under the same work rolls condition with $50 \mathrm{~mm}$ diameter steel roll, the growth of edge crack is intense when the viscosity of the

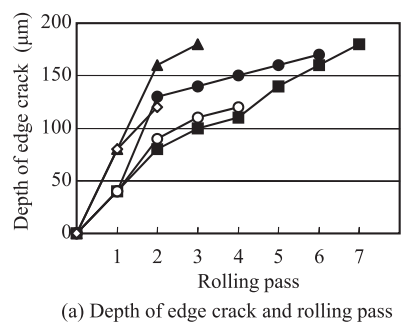

Fig. 7. Relation between thickness and depth of edge crack.

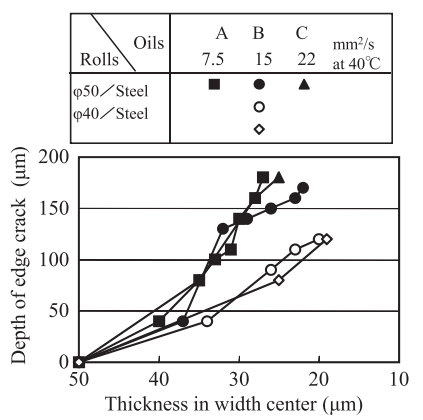

(b) Depth of edge crack and foil thickness 


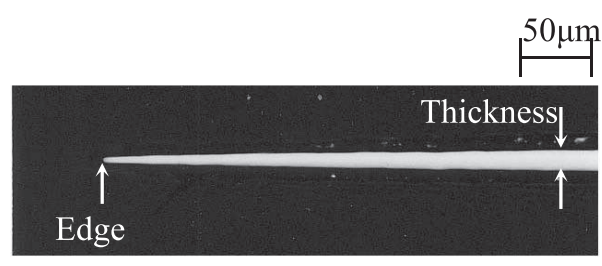

(a) Rolled by $\varphi 50$ Steel WR / Oil B

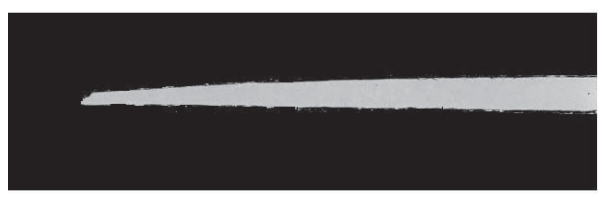

(b) Rolled by $\varphi 40$ Steel WR / Oil B

Fig. 8. Cross section of foil edge.

rolling oil is high that leads to high reduction in thickness.

Figure 7(b) shows the relation between foil thickness and the edge crack depth after each rolling pass. From this figure, it is understood that the foil thickness and the edge crack depth shows good correlation regardless of the rolling oil conditions. Here, rolling force and tension conditions were same as shown in Table 1. However, when work roll diameter is small, edge crack depth of the same thickness is shallow. Moreover, when the Young's modulus of the roll is large, it is understood that the edge crack is slightly shallow. That is, with respect to the rolling limit owing to the edge crack, it can be said that smaller roll diameter and higher Young's modulus is advantageous.

\subsection{Influence Factor on Edge Crack in the Foil Rolling}

The state of foil edge was observed in detail. Figure 8 shows the microscopic photographs of cross section at edge portion of rolled foil. Figure $8(\mathrm{a})$ is edge part section of rolled foil using steel roll of $50 \mathrm{~mm}$ diameter work rolls, and Fig. 8(b) is that of $40 \mathrm{~mm}$ diameter. The thickness at center in width direction is $25 \mu \mathrm{m}$. In Fig. 8, it turns out that the thickness in foil edge of (a) is thinner than that of (b). In other words, strip thickness at edge portion rolled with larger diameter work rolls decrease more even if the thickness at width center is same. This phenomenon is known as the edge drop that strip edge thickness decreases rapidly. ${ }^{12)}$ The edge drop is caused by sharp change of roll flattening nearby strip edge portion. This means that the rolling conditions for small roll flattening contribute to reduce the edge drop.

Figure 9 shows the relation between foil thickness and depth of edge crack. In Figs. 9(a) and 9(b), thickness at width center and foil edge are used respectively. The depth of edge crack shows good correlation with thickness at foil edge in Fig. 9(b).

Based on detailed observation of foil edge phenomenon, good correlation between edge crack depth and foil thickness at extreme edge is found. From these experimental
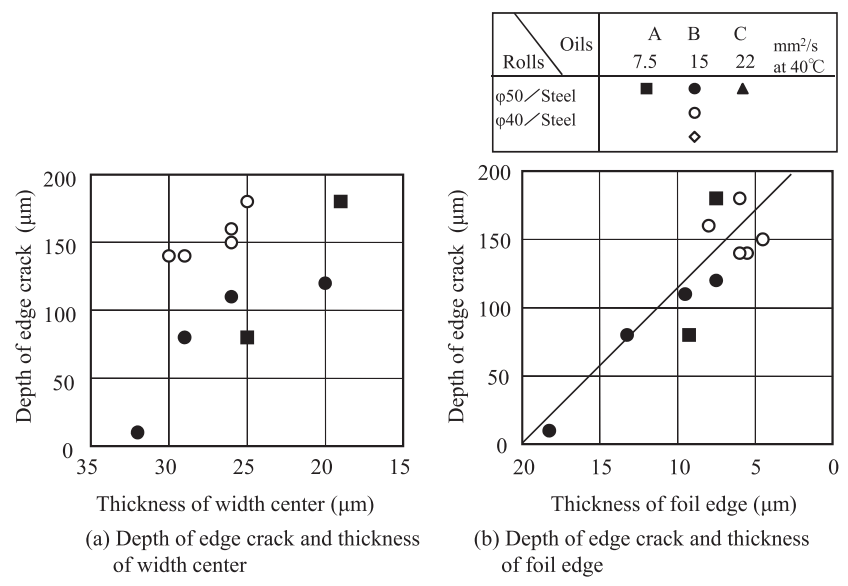

Fig. 9. Foil thickness and depth of edge crack.

results, it is suggested that the rolling conditions for prohibiting edge drop, such as work rolls with smaller diameter or higher Young's modulus are effective to suppress edge crack expansion.

\section{Conclusions}

Based on experimental analysis about rolling limits and minimum thickness in ultra thin foil rolling, following conclusions are obtained.

(1) Higher viscosity of rolling oils is effective to expand minimum thickness in foil rolling, in addition to smaller diameter and higher Young's modulus of work rolls. New prediction formula for minimum thickness is proposed.

(2) It is suggested that the influence of rolling tension, which is main factor of the stress concentration causing strip breakage must be discussed separately with growth behaviour of the edge crack.

(3) Depth of edge crack has correlation with the thickness of foil edge portion, and it is suggested that the rolling conditions for prohibiting edge drop, such as work rolls with smaller diameter or higher Young's modulus are effective to suppress edge crack expansion.

\section{REFERENCES}

1) H. Sumitomo: J. Jpn. Soc. Technol. Plast., 33 (1992), 904

2) I. Yarita: J. Jpn. Soc. Technol. Plast., 29 (1988), 226.

3) M. Nonnenmann: SAE Technical Paper, No. 850131, (1986).

4) S. Pelters: SAE Technical Paper, No.890488, (1989).

5) H. Shimizu, M. Kohno and K. Yoshioka: Kawasaki Steel Tech. Rep., 31 (1994), 29.

6) K. Fukuda and K. Ishii: Bull. Iron Steel Inst. Jpn., 12 (2007), 585.

7) M. D. Stone: Rolling of thin strip, Iron Steel Eng., 30 (1953), 61.

8) K. Tong and G. Sachs: J. Mechan. Phys. Solids, 35 (1957), 35.

9) H. Ford and J. M. Alexander: J. Inst. Met., 88 (1959-60), 193.

10) W. L. Roberts: Iron Steel Eng., Oct, (1965), 75.

11) S. Shida, Y. Komatsu, K. Yasuda and K. Narita: J. Jpn. Soc. Technol. Plast., 40 (1999), 1066.

12) K. Saxl: Proc. Inst. Mech. Engrs., 22-172 (1958), 727. 